\title{
GLOBAL MONITORING FOR FOOD SECURITY AND SUSTAINABLE LAND MANAGEMENT - RECENT ADVANCES OF REMOTE SENSING APPLICATIONS TO AFRICAN AND SIBERIAN SHOW CASES
}

\author{
Klaus U. Komp ${ }^{1}$ \\ Carsten Haub $^{2}$ \\ ${ }^{1,2}$ EFTAS Remote Sensing Transfer of Technology, Oststrasse 2-18, \\ 48145 Muenster, Germany - klaus.komp@eftas.com
}

\section{Commission VIII, WG VIII/6}

KEYWORDS: Ecosystems, Agriculture, Environment, Monitoring, Land Cover, Change Detection

\begin{abstract}
:
After four decades of space borne remote sensing, the unmapped white patches have mostly disappeared. Those basic information give the foundations to the observation of changes and even the introduction of monitoring programmes for a various number of features in the natural and human landscape of our planet. Recent indicators for climatic change together with worrisome alterations in regional food production versus the constantly increase of human population demand the design and implementation of reliable land management tools which will serve the food security as well as the sustainable use of resources of the ecosystem in its respective regional context. The positive responses and convincing results of ESA service elements in the efforts towards food security in several African countries have been the basis for the transfer of the methods into another region, the Western Siberian corn-belt. The large extends of cropping schemes in West Siberia demand advanced remote sensing methods to be applied in order to compare the impacts of climatic change not only on the agricultural production but also on risks for the ecosystem. A multi scale approach of remote sensing methods is introduced in analogy to the African activities. An adopted monitoring concept is developed using a nearly daily product of medium resolution for wide areas, high resolution sensors for stratified sample areas and in-situ observations. Beyond methodological research, the ability of remote sensing is contributing to operational solutions that can ensure the nutritional and ecological future of our planet.
\end{abstract}

\section{KURZFASSUNG}

Nach vier Jahrzehnten Satellitenfernerkundung sind die meisten weißen Stellen auf der Weltkarte verschwunden. Solche Basisinformationen sind die Grundlage für die Beobachtung von Veränderungen und erlauben sogar den Einstieg in das systematische Monotoring einer Vielzahl von Elementen der natürlichen und anthropogenen Landschaften unseres Planeten. Rezente Indikatoren eines Klimawandels sowie Besorgnis erregende Veränderungen regionaler Ernährungsproduktion bei weiterem Bevölkerungswachstum erfordern die Entwicklung und Implementierung verlässlicher Landentwicklungsinstrumente, die sowohl der Ernährungssicherung wie auch einer nachhaltigen Ressourcennutzung des Ökosystems im regionalen Kontext dient. Das positive Echo und überzeugende Ergebnisse der ESA Serviceelemente für Ernährungssicherung in verschiedenen afrikanischen Staaten waren die Grundlage für die Methodenübertragung in eine andere Region, den westsibirischen Getreidegürtel. Die großräumigen Anbaumuster Westsibiriens erfordern die Anwendung erweiterter Fernerkundungsmethoden, um die Klimafolgenabschätzung nicht nur hinsichtlich der Agrarproduktion, sondern auch hinsichtlich der Ökosystemrisiken zu untersuchen. Analog zu den afrikanischen Aktivitäten wird ein mehrstufiger Ansatz von Fernerkundungsmethoden implementiert. Dazu gehört ein angepasstes Monitoringkonzept, das nahezu tägliche Produkte mittlerer Auflösung großflächig nutzt, sowie HR-Sensoren für stratifizierte Stichprobenflächen und Feldbeobachtungen. Die Leistungsfähigkeit der Fernerkundung trägt dazu bei, dass jenseits methodischer Forschung auch operationelle Lösungen die ernährungssichernde und ökologische Zukunft unseres Planeten sichern.

\section{INTRODUCTION}

Since the early 1970ies civil space borne remote sensing has been contributing to a second discovery of the world, the white patches of our maps have mostly disappeared. Those basic information give the foundations to the observation of changes and even to the introduction of monitoring programmes for various features in the natural and human landscape of our planet, like the changes by flooding, or draught, landslides or erosion, deforestation or desertification, land cultivation or urban sprawl and many more. Recent indicators for climatic change together with worrisome alterations in regional food production versus the constantly increase of human population demand the design and implementation of reliable land management tools which will serve the food security as well as the sustainable use of resources of the ecosystem in its respective regional context.

The Global Monitoring for Food Security (GMFS) focuses on those aspects of food security monitoring where satellite derived technology can bring added value. These include monitoring parameters reflecting crop condition, agricultural production and overall vegetation health. For test areas, it has established an operational service for crop monitoring in support of Food Security that can serve policy makers and operational users on various scales by providing spatial information on variables that affect Food Security. In view of the global need for improved food security and sustainable land management schemes, the paper investigates the potential of methodological transfer of the African results into a moderate climate environment. The SASCHA project focuses on regional shifts of agricultural production in consequence of changing environmental conditions. The joint reflection of different land management developments in different continents is using comparable methodological tools. The system adapts existing technologies from the Global Monitoring for Environment and Security (GMES) initiative to region-specific LULC classes.

The motivation for this article is the long term experience that around the world there are always the rural areas that suffer 
from incomplete or inconsistent maps and environmental data. Several studies have been executed by the United Nations which proof that rural areas have been mapped in smaller scales only and have not been updated for many years (e.g. Brandenberger 1987). The same applies for environmental data and GIS data bases. Only if we develop methods and operational approaches to monitor the rural environment, which means also the agricultural land use, we will gain spatial information to improve sustainable land management and food security.

Related approaches have been earmarked by the World Bank, from the German Agency for International Cooperation and even the Millennium Challenge Corporation for many years, but without really turning around the situation of rural areas around the world (cf. Falloux 1989). Therefore the article describes a demand driven approach using remote sensing within a processing chain as technology which can be managed in the hands of agronomic experts with local knowledge.

\section{SUSTAINABLE LAND MANAGEMENT AND FOOD SECURITY}

\subsection{Reciprocity between Food Security, Land Management and Climate}

The importance of the issues on food security and land management becomes obvious when looking at the following figures:

- Currently more than 1 billion people on earth are affected by hunger and more than 30 countries are experiencing food emergencies (cf. FAO 2009).

- Global population passed the 7 billion milestone in 2011 and will reach 10 billion by 2050. (cf. Crossette 2011)

- $40 \%$ of all internal conflicts over the last 60 years have had a link to natural resources (cf. UNEP 2011)

- Biofuel production has increased sharply in the past few years (cf. Flammini 2008; Godvina 2010).

These alarming figures underline the overall significance of a responsible use of natural resources, which demands a monitoring of the current developments, and the research for improved methodological tools to be integrated into operational applications. Although the mapping or monitoring of complex agro ecological aspects by highly specialist remote sensing experts is done far away from the target areas, this innovative approach focuses on bringing adapted but easy to handle processing tools to the local experts.

\subsection{Operational Remote Sensing Services to Agriculture and Land Tenure}

The impacts of climate change, disasters and conflicts, soil and land degradation versus the increasing demand on food and energy production and the increasing global population span an area of conflict targeting land as prime ecosystem resource. Questions such as:

- How many people can be sustained on earth?

- Which land resources are threatened through climate change?

- What kind of land use change will be caused through an increasing production of biofuels?

- What potentials can an increased agricultural production provide in order to reduce the conflict between land degradation and land loss and the increasing pressure on the remaining land resources? are discussed diversely. Tools to measure, describe, and assess sources and impacts of these land use conflicts request enormous efforts, but given the complexity, they are still not sufficient to provide answers. Although these conflicts have a global dimension their sources and solutions are at a regional or local level. Solutions by means of land resource management systems need to involve the regional and local stakeholders' networks. As such, geospatial information derived from satellite earth observation can contribute to implement structures for sustainable land management systems.

GMFS and SASCHA services are designed to contribute to this. Based on the highly innovative developments at the latest status of research and technologies, stakeholders of various thematic domains can get access to geospatial technologies but without the need to be experts in remote sensing or GIS. The processing tools are designed for experts and operators skilled in the fields of agricultural statistics or nature conservation who are non remote sensing experts. Either through very robust and clear processing steps (see indicative fAPAR maps processing below) or through advanced software developments which are systematically integrated into platforms, providing instruments with easy to use interfaces, but having access to advanced optical and radar remote sensing processing routines in the background. Specifically the software tools such as ALIS (C (see CuA processing and SASCHA application below) will facilitate knowhow and technology transfer and increase the availability and access for up to date remote sensing methodologies to non remote sensing experts, but also contribute to multi-scale geo information systems.

Through the RCMRD as GMFS's regional coordinator, a sustainable and operational structure is available which is mandated to support the training, access and transfer to the different national and local users. Further to this, the Federal Ministry of Agriculture in Sudan and the Ministry of Agriculture and Food Security in Malawi are involved as direct GMFS beneficiaries at national level. In this respect the GMFS Agricultural Monitoring services are well designed for a successful, very useful and sustainable user driven technology transfer.

The Federal Ministry of Agriculture (FMoA) in Sudan requested GMFS to investigate EO contributions to the agricultural monitoring in particular the assessment of traditional rain fed areas. It is understood that monitoring and statistics frameworks in this sector are a difficult issue, since the infrastructure in the traditional rain fed areas is low, the areas are huge, and the large seasonal variations have an impact on the distribution and location of cultivated area. Due to this, adequate sampling schemes are required each year and inter annual comparisons are important. In this respect GMFS was requested by the FMoA and consulted by the GMFS Steering committee to step in via an enhanced integration of Remote Sensing at two different scales into the agricultural monitoring framework.

The first required products are cultivated area maps at a scale of 1:50.000, based on recently acquired HR optical and SAR data to support the Sudanese user institutions in monitoring agriculture production in Sudan.

The second requirement is to generate an indicative map of vegetation growth activities as early as possible, at a scale of 1:1000.000 based on Medium Resolution MERIS imagery before the harvest in Sudan in order to create information to better coordinate the given resources for field survey and interviewing campaigns. 


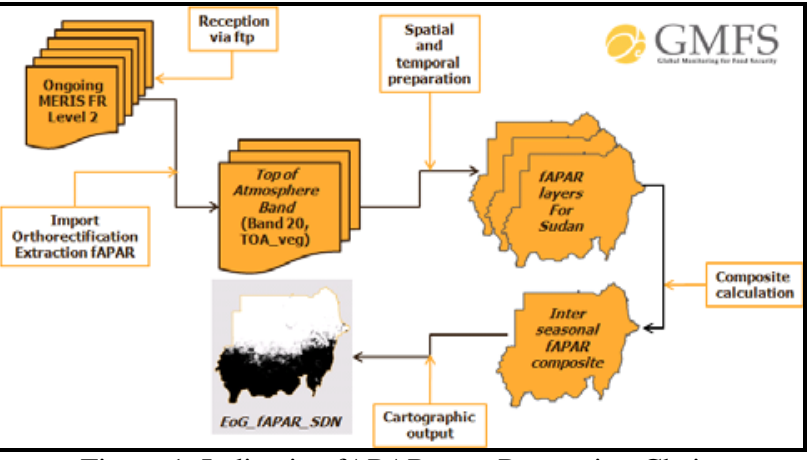

Figure 1 Indicative fAPAR map Processing Chain

The processing chain developed in the frame of GMFS is depicted schematically in fig. 1 and shows that there are ongoing remote sensing data from the MERIS FR level 2 products and the data from the top of atmosphere band introduced into the processing chain. The GIS operations, with spatial data from the project data base concerning orthorectification and different reference layers, allow the creation of the cartographic output of the mid September situation in a short time already in September, well before the beginning of the harvest period in October.

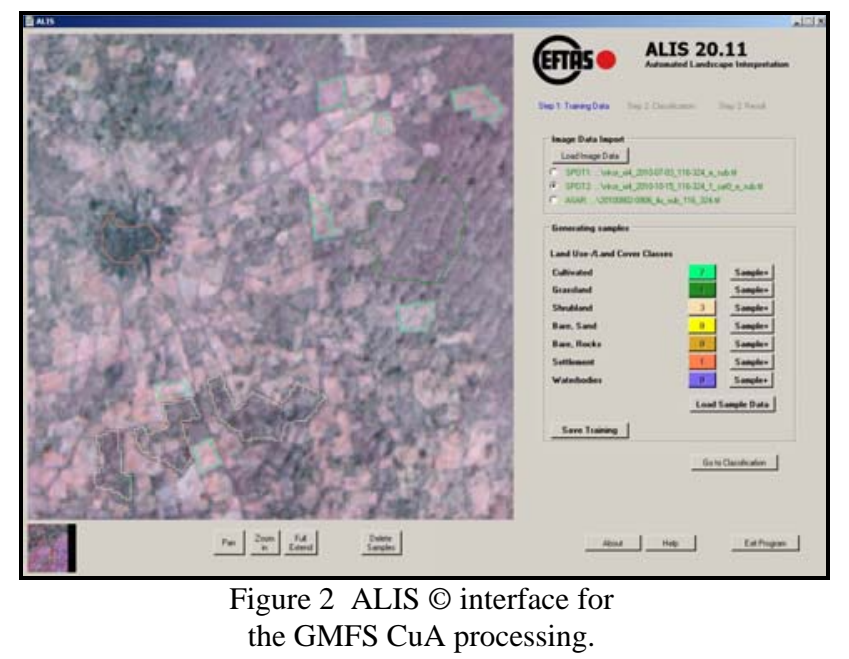

The creation of the annual cultivated area map uses the ALIS (C) software interface developed in the frame of the GMFS project, of which a screenshot is displayed in fig. 2.

\subsection{Application Sites in the Sudan and beyond}

The remote sensing community has developed a bundle of worthy tools for change detection of land cover which have grown beyond academic research into stable and reproducible application instruments. These achievements have been the precondition for the transfer of technology into the regional application in African administrative environments. This transfer was one of the driving goals for the European Space Agency (ESA) to start the project series of "Global Monitoring for Food Security in Africa” (GMFS) ten years ago. GMFS is part of ESAs contribution to the European Union / ESA Global Monitoring for Environment and Security (GMES) programme. It is the main European GMES Service Element in support of food security monitoring systems with remote sensing and GIS applications serving the food security sector in African countries like Senegal, Mali, Niger, Sudan, Ethiopia, Malawi, Zimbabwe and Mozambique. A consortium of seven European R\&D partners (see acknowledgements) jointly developed technical specifications and methodological improvements in remote sensing applications to early warning, biomass forecast, agricultural mapping, change maps, soil moisture indicators and agro statistical survey. All these efforts were brought together into for training and implementation modules, together with the local partner organisations in the agro environmental administrations of the participating countries.

The GMFS Service Portfolio is structured into three top-level service types. The agricultural monitoring service type provides processing routines to assess total planted crop land and its variability from one year to another with specific emphasis on the traditional rain fed agriculture production in Sudan. Agriculture production in Sudan is largely depending on seasonal variability and distribution, intensity, duration and period of rains. Large areas in the central Sudan are depending on traditional rain fed agriculture with the cropping of Sorghum and Millet mainly for personal consumption. This causes high vulnerability of a certain part of the Sudanese population. About $60 \%$ of the Sudanese population are living in rural areas with an average population density of 14-17 people per $\mathrm{km}^{2}$.

The set up of a robust monitoring scheme was initiated during the past decades with a number of attempts, upon which the FMoA could elaborate a basis on how to usefully integrate Remote Sensing technologies with ground observations. In the past, however, those failed due to political reasons. Recent elaborations from GMFS demonstrated a huge progress in monitoring cultivated areas.

But, and there the general difficulties of monitoring the traditional rain fed areas cross the limitations of Remote Sensing, the electromagnetic characteristics of the traditional rain fed crops and the timely development over the crop season is hardly to distinguish from natural vegetation or fallow land vegetation. Tests were carried out to apply new generations of sensors, such as very high resolution radar and optical with certain improvements. But operationability could not be achieved due to the non-availability of multi time series data on the administrative reporting level which is the level of federal states in Sudan (see fig. 3).

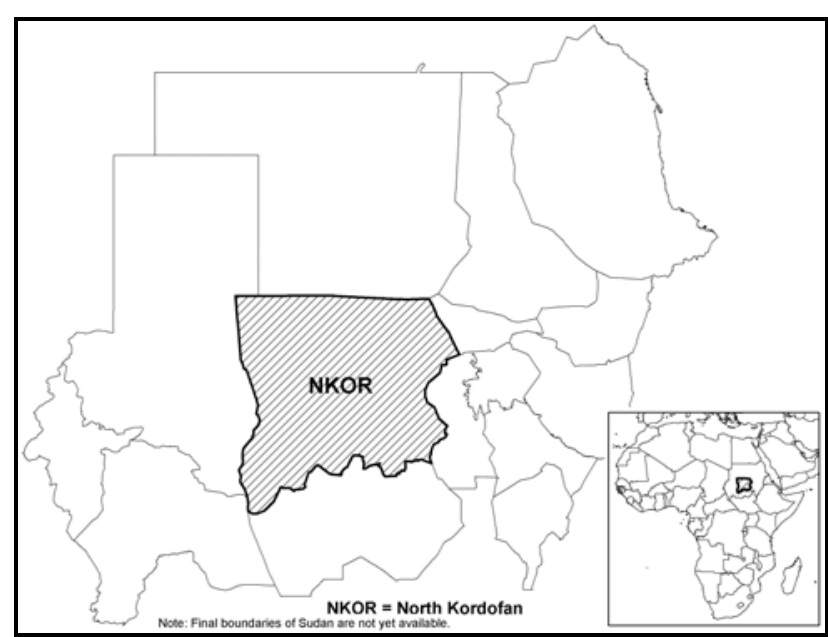

Figure 3 Localization of actual Test site in Sudan

(North Kordofan state, approx. 240,000 km²)

The recent GMFS Agricultural Mapping processes must be adopted and enhanced with additional routines and more in depth context knowledge from Sudanese experts in order to bet- 
ter extract low intensity agriculture. In addition to the development and adaptation of existing algorithms a specific request is the successful integration of these into a strong logistical framework within the FMoA, in order to bring together the advanced knowledge to elaborate and apply mapping processes and the regional knowledge on contexts of the production types. On basis of the ESA and third party mission sensor portfolio, the established institutional collaboration network, which GMFS established during the past years, is bringing together both aspects.

Extracted from the ENVISAT MERIS Full Resolution (FR) level 2 products $(\mathrm{GSD}=300 \mathrm{~m})$, the Fraction of Absorbed Photosynthetically Active Radiation (fAPAR) is derived. Data of the fAPAR type are biophysical variables directly correlated with the primary productivity of the vegetation, and they reflect the fraction of the solar energy which is absorbed by the vegetation within each pixel.

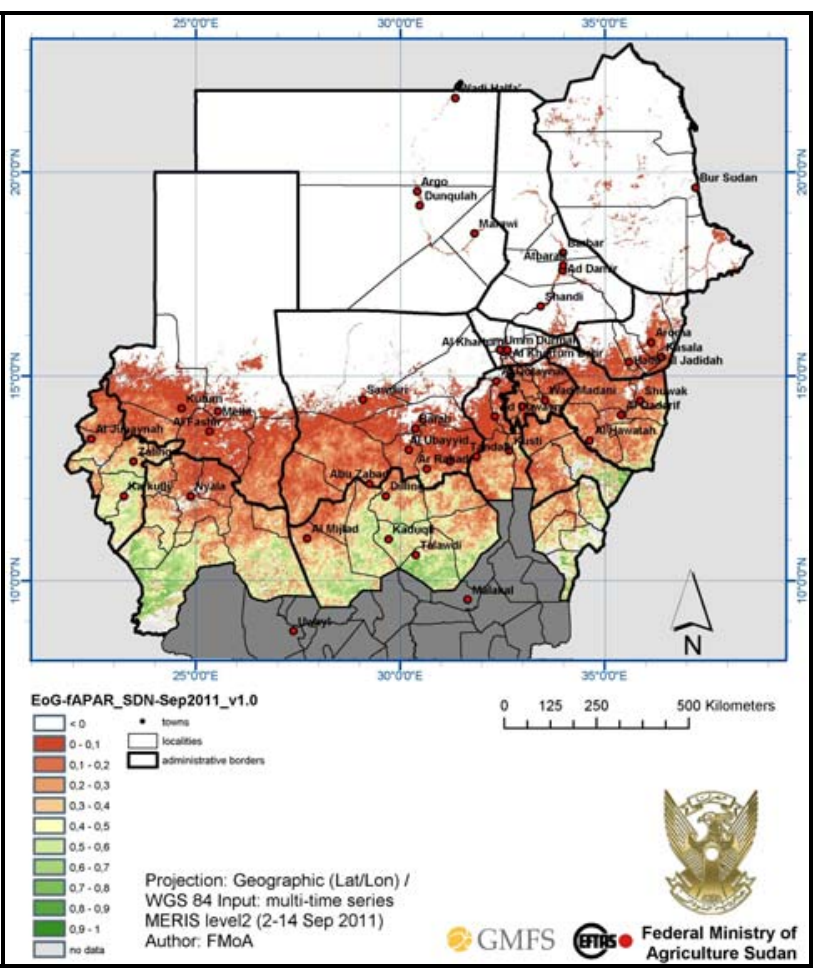

Figure 4 Indicative inter seasonal vegetation growth map (fapar-EoG) for September 2011

Within the framework of the GMFS project, we have elaborated and transferred a processing chain for the generation and analysis of these indicative fAPAR inter seasonal maps (see fig. 4) to the FMoA in Khartoum.

Figure 5 shows the distribution of potential rain fed areas between the crop seasons 2009 (light yellow) versus 2010 (hatched light brown) in North Kordofan State, Sudan (Brockmann 2011). The thematic overlays show a decrease from North to South of the potentially cultivated area in the Eastern part of the state, while at the same time an increase is observed from the South towards the North in the Western part of the state. Compared to the official statistics of the FMoA, which estimate an increase of $10 \%$ of production in North Kordofan for the same period, the satellite data obviously indicate that there is much more spatial differentiation needed. Based on those annual EO application results, the FMoA is now improving its monitoring framework for the benefit of the rural population in the fragile environment of traditional rain fed agriculture.

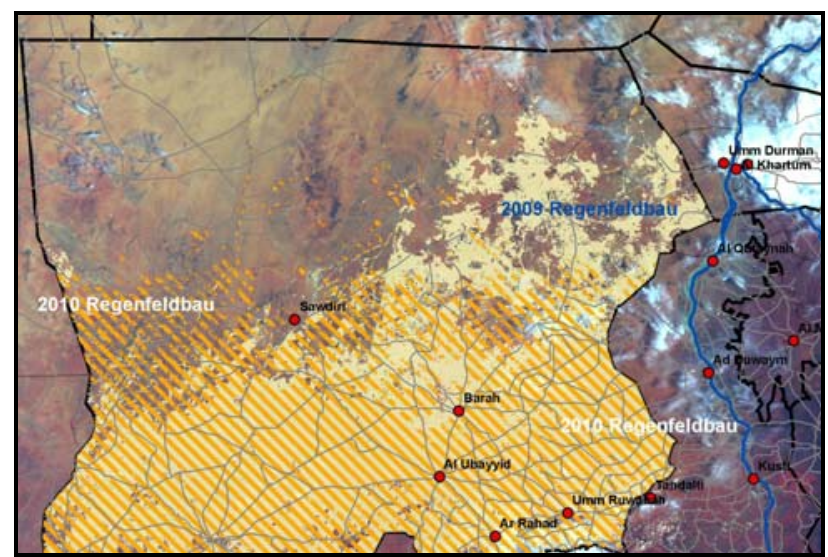

Figure 5 ENVISAT MERIS FR false colour composite (2010-09-12 - bands 13-5-1) overlaid with MERIS FR level 2 fAPAR data from 2009 versus 2010

The results in the application sites confirm the approaches by means of annual monitoring of the variation in the extend of the rain fed agriculture and special indicators like in season fAPAR maps, which are transmitted to the local units of the respective Ministries of Agriculture. Together with specific training modules and joint user conferences, the basis of spatial knowledge is a pertinent improvement of the day-to-day working basis for the African project partners.

\subsection{Application Sites in the Western Siberian Corn Belt}

2.4.1 Transfer Approach: The positive responses and convincing results have been the basis for the transfer of the methods into another region, the Western Siberian corn-belt. In a joint programme funded by the German Ministry for Education and Research and the Russian Ministry of Research, the project called "Sustainable Land Management and Adaption Strategies to Climatic Change for the Western Siberian CornBelt" (SASCHA) was started one year ago. The large extends of cropping schemes in West Siberia demand advanced remote sensing methods to be applied in order to compare the impacts of climatic change not only on the agricultural production but also on risks for the eco system. The experiences from the African activities will also introduce a multi scale approach of remote sensing data. From a nearly daily product of medium resolution (typically MERIS with 300m GSD) for wide areas, and high resolution sensors for stratified sample areas once per season to very high resolution data for stratified spot observation, the project will develop and establish an adopted monitoring concept.

The project SASCHA investigates interactional effects of climate and land-use change on natural resources and ecosystem functions in the Pre-Taiga and Forest-Steppe ecotone of Western Siberia. The interface between the steppe and the northern forest zone in Western Siberia is of global significance in terms of carbon sequestration, food production, and biodiversity. Affecting all these subject matters, climate change and rapid socio-economic development will trigger fundamental land use changes. The analysis of these former, present and future changes and their implications for essential ecosystem functions are the focus of the first project phase. Subsequently, sustain- 
able land-use practices and adaption strategies to climate change will be developed. There were three test sites determined in cooperation between the Russian and German partners, all in the Siberian corn belt to the South East of the city of Tyumen (fig. 6), named according to populated places nearby.

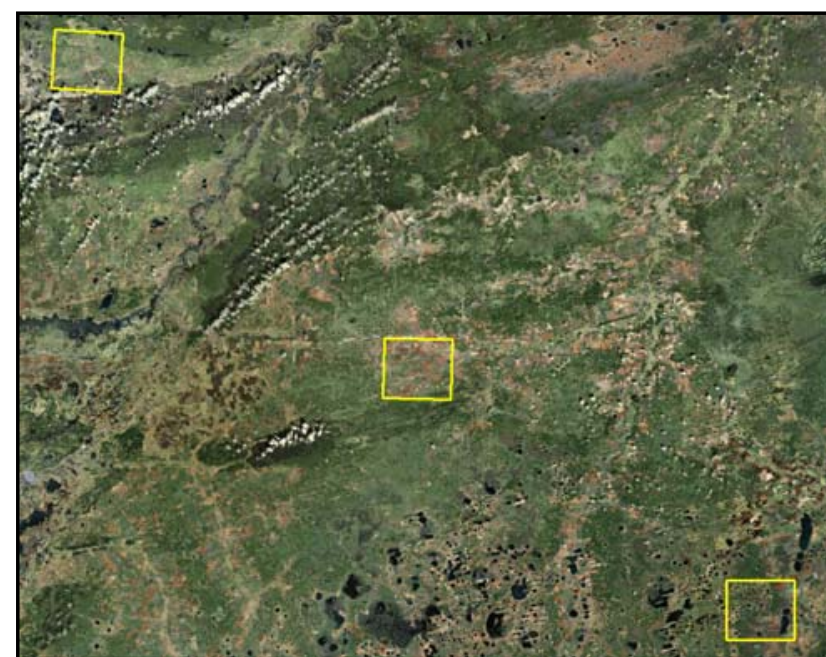

Figure 6 Localization of SASCHA test sites (Western Siberia) (left: Kaskara, middle: Omutinsky, right: Ishin)

2.4.2 Monitoring of Changes in Agriculture, Biodiversity and Carbon Stocks for Landscape Planning: The second project phase is dedicated to the implementation of monitoring tools for a wise and sustainable future land use in the region. As already identified by relevant European directives such as INSPIRE (Infrastructure for Spatial Information in Europe), Water-framework directive, and Habitat directive, land use and land cover (LULC) datasets are an indispensible prerequisite for the support of stakeholders in environmental policy.

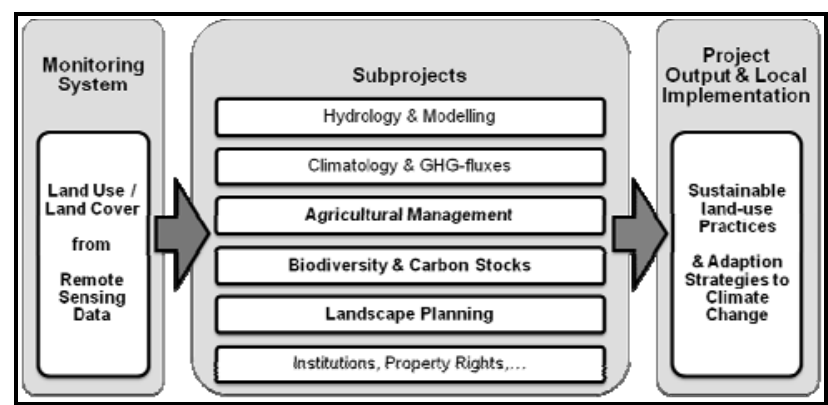

Figure 7 Acquisition of land use changes with remote sensing data in the SASCHA project

Derived from this experience, the efficient collection of reliable up-to-date LULC data is one major issue in the context of the development and implementation of a sustainable land management system for the pilot region, theTyumen Oblast. Figure 7 depicts the interoperability of the monitoring system with the planned project results, and the potential for local implementation through the different approaches of the subprojects, all serving the achievement of the common results (cf. Voelker 2011).

The SASCHA subproject 'Analysis and Monitoring of Land Cover and current Land-Use Change' has started to develop, evaluate and implement a prototype system for the extraction of LULC information from remote sensing images. A core issue is the development of change detection methods and the implementation of adequate image analysis algorithms, especially for agricultural LULC changes, such as the expansion and intensification of arable land. The system adapts existing technologies from the Global Monitoring for Environment and Security (GMES) initiative to region-specific LULC classes and aims to enable a (semi-)automatic detection and quantification of future LULC changes with a software interface that is user-friendly and easy to use: the ALIS (C) interface (cf. fig. 2). The system development will be driven by user needs collected from stakeholders of the Oblast's Departments for Environmental Protection and Agriculture.

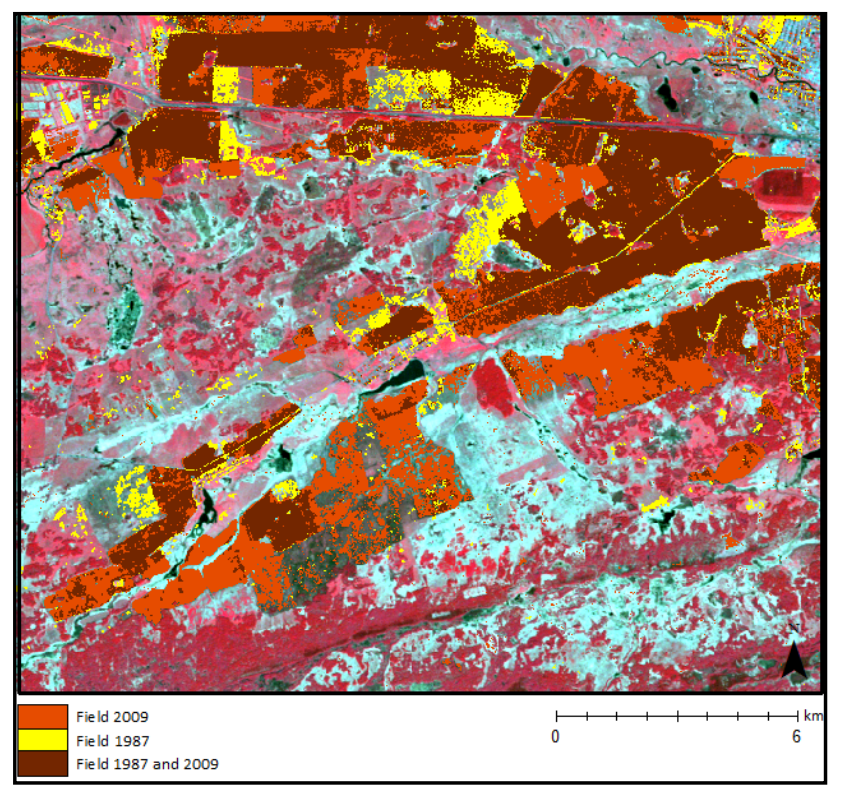

Figure 8 Change detection of agricultural land use in the SASCHA test site of Omutinsky (Tillmann 2012)

To monitor the assumed northward shift of agriculture the technique of remote sensing is considered to be appropriate to the large extend of agricultural schemes in Western Siberia. The first results of the ongoing project are taken from Tillmann 2012 using available archive data from 1987 and 2009 of the Landsat satellites (cf. fig. 8). The land use changes give evidence to a considerable increase of agricultural use and relatively few abandoned sites. Detailed investigations have started and will include additional parameters from the other subprojects in order to detect driving factors for the spatial changes.

Only with a reliable spatial analysis of the current threats and factors for change will it be possible to develop sustainable land use practices and promising adaption strategies to environmental changes, in cooperation with the regional authorities and stakeholders.

\subsection{Advances in Remote Sensing Methods and Potentials for Transfer}

Advances in remote sensing from related research have been used, improved and incorporated in operational processing chains. The related investigations on this topic from Calvet 2010, Listner 2011 and Mariotto 2011 have been reflected to improve the own knowledge based methodologies, when developing the ALIS (c) interface, which serves already in different working environments. The close cooperation of universities, R\&D companies and administrative users has lead to stable 
transfers from science to applications, according to the demand of the competent administrations.

\section{CONCLUSIONS}

The attempt to install synergies between the described research projects with quite different regional, socio-economic and environmental conditions is certainly challenging. On the other hand it is very helpful to experience that despite all the different pre-conditions, there are also some common issues to be found, which threaten the living conditions of the future generations. The world's responsibility for improvements in sustainability of the land management will become the basis for environmental security and food security of our planet. The current investigations show the part remote sensing and GIS play in contributing to the dissemination of better tools for land management and food security in order to ensure the involvement of the regional stakeholders and expertise to reach operability.

\section{REFERENCES}

Brandenberger, A. J., Gosh, S. K., 1987. Status of the World Topographic and Cadastral Mapping. In: United Nations: World Cartography, vol. XVII, pp. 94-124.

Brockmann, J., Haub, C., Komp, K., 2011. Global Monitoring for Food Security Stage 3 (GMFS 3). Photogrammetrie Fernerkundung Geoinformation, 2011(3), pp. 194-195.

Bydekerke, L. \& al., 2007. The Global Monitoring for Food Security Project: using ENVISAT MERIS and ASAR for Monitoring Agriculture in Africa. In: 32nd International Symposium on Remote Sensing of Environment: Sustainable Development through Global Earth Observations with ISPRS WG VII/6 special session.

Calvet, J.-Ch. \& al., 2010. Monitoring Soil and Vegetation Fluxes of Carbon and Water at the Global Scale: Towards a GMES Service. In: Proc. 'ESA Living Planet Symposium', Bergen, Norway, 28 June - 2 July 2010 (ESA SP-686, Dec. 2010)

Crossette, B.; Kollodge, R., 2011. State of world population 2011 - People and possibilities in a world of 7 billion. New York, 2011. Published by UNFPA.

(www.unfpa.org/public/home/news/pid/8769).

Falloux, J., 1989. Information spatiale et télédétection pour la gestion des ressources renouvables - Un approche axé par la demande. Banque Mondiale, 108, 1989 Washington.

FAO, 2009. FAO World Summit on Food Security, Rome, 16.17.11.2009 (www.fao.org)

Flammini, A., 2008. Biofuels and the underlying causes of high food prices. GBEP-FAO, Rome.

Govinda, R. \& al., 2010. Biofuels Markets, Targets and Impacts. World Bank Policy Research Working Paper 5364. The World Bank, Washington 2010.

Haub, C., 2007. GSE Global Monitoring for Food Security (GMFS). In: Food Security Information Services for Africa Bridging the Divide through Partnerships. Wichmann Verlag. Heidelberg, pp.154-161.
Haub, C. et al., 2008. Crop Mapping Services for the Sudanese Government in Frame of the ESA Global Service Element "Global Monitoring for Food Security". Photogrammetrie Fernerkundung Geoinformation, 2008(5), pp. 409-419.

Haub, C., Gilliams, S., 2011. Food Security: Crop Monitoring from the Sky. Geospatial World, 2011 (3), pp. 42-45.

Listner, Cl. \& Niemeyer, I., 2011. Object-based Change Detection. Photogrammetrie Fernerkundung Geoinformation, 2011 (4), pp. 233-245.

Malinverni, E. S., 2011. Change Detection Applying Landscape Metrics on High Remote Sensing Images. Photogrammetric Engineering \& Remote Sensing, 77(10), pp. 1045-1056.

Mariotto, I., Gutschick, V. P., Clason, D. L., 2011. Mapping Evapotranspiration from ASTER Data through GIS Spatial Integration of Vegetation and Terrain features. Photogrammetric Engineering \& Remote Sensing, 77(5), pp. 483-493.

Tillmann, Cl., 2012. Supervised classification and change detection of agricultural land use in the forest steppe zone of West Siberia using multi temporal satellite images. University of Muenster, Germany, Master thesis (in preparation)

UNEP, 2011. www.unep.org.

Voelker, A., Mueterthies, A., Hoelzel, N., 2011. Implementation of a monitoring system for land cover changes in the Western Siberian corn-belt - A remote sensing approach from the SASCHA project. In: Environment and Natural Resource Management, Tyumen 2011. p. 233.

\section{ACKNOWLEDGEMENTS}

MERIS-Data: (C EUROPEAn Space Agency, Via Galileo Galilei, I-00044 Frascati (Rome), Italy (figures 4 \& 5).

RapidEye-Data: @ RapidEye Copyright 2010 (figure 2).

Landsat-Data: ( ) 1987, 2009 (figures 6 \& 8).

The GMFS Consortium is composed of the following institutions: VITO - Belgium, EFTAS - Germany, SARMAP Switzerland, University of Liege - Belgium, Conzortio ITA Italy, EARS - Netherlands and GeoVille - Austria. GMFS is funded by ESA.

The SASCHA Consortium is composed of the following institutions: Germany: University of Münster, EFTAS Remote Sensing Transfer of Technology, University of Kiel, University of Osnabrück and University of Applied Science of Osnabrück, Humboldt University of Berlin; Russian Federation: Tyumen State University, Tyumen State Agricultural Academy, Tyumen Government (Departments of Agriculture, Ecology \& Subsoil Use, Strategic Planning). SASCHA is co-funded by the German Ministry of Education and Research and by the Russian Ministry of Research. 